\title{
Impacts of Western Popular Culture on Youths in Hawassa City, South Ethiopia
}

\author{
Getalem Aychew Beyene*, Armaye Debebe Eshete
}

Mahibere Hiwot for Social Development, Bahir Dar, Ethiopia

Email address:

gechlove44@gmail.com (G. A. Beyene), armayedebebe@gmail.com (A. D. Eshete)

\section{To cite this article:}

Getalem Aychew Beyene, Armaye Debebe Eshete. Impacts of Western Popular Culture on Youths in Hawassa City, South Ethiopia. Humanities and Social Sciences. Vol. 3, No. 3, 2015, pp. 111-115. doi: 10.11648/j.hss.20150303.12

\begin{abstract}
Background: With the expansion of technological progress in mass communication, consuming western popular culture has come to be a valuable activity for youths. The objective of this study was to examine youth's exposure to the western media and cultural products and the potential consequence of this exposure. Methods: School-based "sample survey design" were employed in Hawassa city from 1 April to 1 May, 2012. A total of 125 sample were included in the study. Pre tested self administered structured Amharic questionnaire and in-depth interview techniques were used to collect the data. Simple statistical methods were used to analyze the quantitative data. A framework of analysis technique which is developed along with the interview guides were used to analyze the qualitative data. Results: usage of western media by the youth now seems to reach a stage that could affect young people's perception and feelings toward westerns and their products in a substantial way. As far as the behavioral impact of the usage of western media and popular cultural products is concerned, this study only examined the likelihood of the youngsters to model after the westerns. Moreover, results of this study showed that western media is more likely to exert modeling effect on the youngsters, making it more likely for them to dress and have a hair-do like the different idols portrayed in movies and music clips. Conclusion: While further research is needed to draw definitive conclusions about the impacts on young people of exposure to pornography, the little evidence available provides grounds for serious concern about exposure of young people to different types of pornography.
\end{abstract}

Keywords: Western, Popular Culture, Youth, Hawassa City

\section{Introduction}

As the world becomes more and more globalized, all countries are inevitably experiencing greater informational and cultural exchange with the rest of the world and therefore subjecting themselves to foreign influences. As stated by Giddens, local traditions are joined by a host of additional cultural forms from abroad, presenting people with a confusing array of lifestyle options from which to choose [1]. Established identities and ways of life are giving way to new forms of hybrid 'identity' composed of elements from contrasting cultural sources [2]. Thus, a black African young today might continue to be strongly influenced by the traditions and cultural outlooks of his tribal roots at the same time as he adopts cosmopolitan styles and tastes in dress, leisure pursuits, and hobbies and so forth [3].

Western popular culture has attained an immense global following. At the same time, for many developing countries the near take-over of their own cultural industries, especially for younger audiences, is of great concern [4]. Different western based satellite Television (TV) programs, which deliver most part of western cultural and entertainment product, are now expanding in the city of Hawassa. It is common to see that most adolescent cell phones with audio and video player, iPods, and so on which opened the way to have an easy access to a wide range of western cultural products which means the choice to consume. With the expansion of technological progress in mass communication, consuming western popular culture, be it music, film or other entertainment media, has come to be now a valuable activity for youth [5]. The exposure to these western cultural products makes the youth despise their own culture. In addition exposure to pornography videos and sexually explicit materials challenge the traditional way of sexual expression that leads to youth's high risk sexual behavior [6,7].

While there is an increasing understanding of the influence of western cultural products on youth, enough study has not been conducted in Ethiopia. Therefore, this study was intended to examine the influence of the western popular 
culture, particularly the entertainment cultural media products on youth's behavior and lifestyle in view of filling the existing knowledge gap.

The study can be a base line for different youth programs which: encourage the youth to foster ties with their cultural traditions and cultivate a sense of pride; develop youth's capacity towards creative interaction with foreign cultures; and enable youth to look to the future in a rapidly changing world with a sense of cultural history and thus an identity.

\section{Methodology}

A school-based sample survey method, supplemented with a qualitative method was employed in Hawassa city, South Ethiopia, from 1 April to 1 May, 2012. For the quantitative data, the study employed multi-stage sampling method. The sampling procedure employed is further illustrated below.

Table 1. Sampling procedures to select study participants, Hawassa city, South Ethiopia, April 1to May 1, 2012.

\begin{tabular}{|c|c|c|c|c|c|c|c|c|}
\hline Selected Schools \& Colleges & \multicolumn{2}{|c|}{ Preparatory 1} & \multicolumn{2}{|c|}{ Preparatory 2} & \multicolumn{2}{|c|}{ College 1} & \multicolumn{2}{|c|}{ College 2} \\
\hline Selected Classes & $\mathrm{X} 1$ & Y1 & $\mathrm{X} 2$ & Y2 & $\mathrm{X} 3$ & Y3 & $\mathrm{X} 4$ & $\mathrm{Y} 4$ \\
\hline No of Students & 60 & 67 & 59 & 51 & 55 & 63 & 65 & 59 \\
\hline Sum of every $K^{\text {th }}$ & 15 & 17 & 15 & 13 & 14 & 16 & 17 & 18 \\
\hline Sub Total & & 2 & & 28 & & 30 & & 35 \\
\hline Total & & & & & 125 & & & \\
\hline
\end{tabular}

For the qualitative data, few key informants were selected from those who had fully participated in the survey by using purposive sampling technique. A face to face interview was conducted by using structured Amharic (the local language) questionnaire. An open-ended and responsive questioning was employed to address some questions in relation to the effects that result from the exposure to pornography and sexual media content. The interview was held with five male and three female informants. Regarding to the quantitative data analysis, responses obtained from the structured questionnaire were organized on the logical consistency and structure of responses. Simple descriptive statistical methods as, frequency distribution, tabulation and percentage distribution were used to analyze and describe the data. With regards to the analysis of qualitative data, the findings obtained in interview were tape-recorded and these records were transcribed and categorized under each interview topic and theme. Data analysis was done using a framework of analysis, which was developed using the study themes. The framework of analysis was revised when additional issues emerged from the data.

\section{Result and Discussion}

\subsection{Socio Demographic Characteristics of Respondents}

Table 2. Socio demographic characteristics of respondents, Hawassa City, South Ethiopia, April 1 to May 1, $2012(n=125)$.

\begin{tabular}{lll}
\hline Characteristics & Category & No (\%) \\
\hline Sex & Male & $59(47.2)$ \\
& Female & $66(52.8)$ \\
Age & $15-19$ & $47(37.6)$ \\
& $20-24$ & $64(51.2)$ \\
Educational level & $25-29$ & $14(11.2)$ \\
\multirow{3}{*}{ Religion } & Preparatory & $60(48.0)$ \\
& College & $55(52.0)$ \\
& Orthodox & $39(31.2)$ \\
& Muslim & $27(21.6)$ \\
& Catholic & $14(11.2)$ \\
& Protestant & $45(36.0)$ \\
\hline
\end{tabular}

A total of 125 (59 female, 66 male) students were included in this study (response rate $=100 \%$ ). The majority of the study subjects lie in the age group 20-24 (51.2\%). With regard to the educational level, $52 \%$ of them are learning in colleges. Regarding religion of respondents the majority (36\%) were protestant followers [Table 2].

\subsection{Forms of Audio Visual-Electronic Media}

Popular culture is manifested around the world through movies, music, television shows and satellite broadcasts among other entertainment products and goods. This study has selectively focused on the image-centered cultural-entertainment products, forms of audio visual-electronic devices were asked (fig.1)

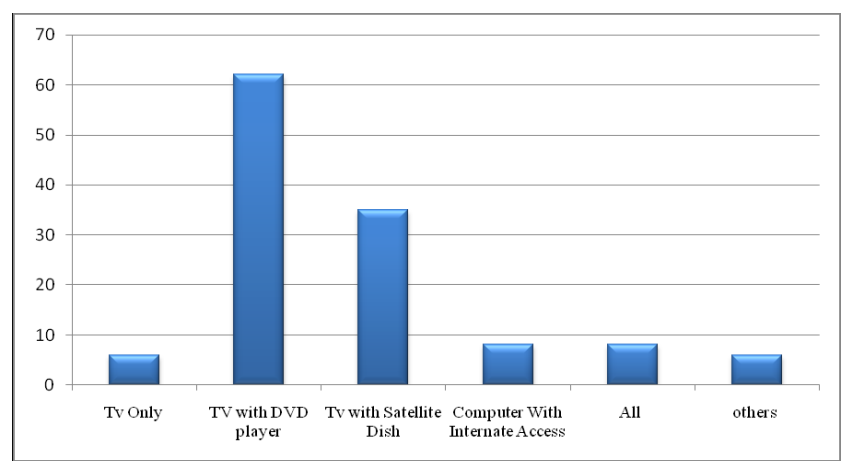

Figure 1. Distribution of respondents by forms of audio visual-electronic medium, Hawassa city, South Ethiopia, April 1 to May 1, 2012.

As shown in the above figure, more than three-fourth of the respondents have access to TV with Digital Video Disc (DVD) player which shows their access to a wide range of cultural-entertainment media products.

\subsection{Exposure to Western Cultural Entertainment Products}

Exposure to western cultural-entertainment media products is quite common among respondents. The finding of this study showed that about $86.4 \%$ respondents reported that they watch different western cultural media products. Among those who reported that they have watched different western made 
movies, TV drama series and music clips $6.5 \%$ watched very often, and $33.3 \%$ watched often. Over half of them who watched these cultural media products do so less often while the rest $8.3 \%$ reported that they watched rarely.

Accordingly, the respondents who watch western made movies/films, TV drama series and music clips "very often" and "often", $6.5 \%$ and $33.3 \%$ respectively, were combined to be taken as having relatively had higher (39.8\%) exposure as western media users. Before directly moving on to see the likelihood of the respondents to model after the different styles of dressing and/or hair-do presented in different western medias, it was found necessary to first look at on their interests in the different styles of dressing and/or hair-do presented in different western movies, TV drama and music clips. This is because their "personal interest" was taken to be significant factor in explaining the likelihood of adopting.

About $53.5 \%$ of the respondents have an interest to adopt western culture, even if their interests vary from intense to moderate. In verifying the modeling effect, the respondents who reported to have an interest in the different styles of dressing and hair-do which they observe in movies, TV drama series or music clips were asked to tell whether they ever have practically adopted them. Correspondingly, their reasons for adopting and not adopting were also identified [Table 3].

Table 3. Taking up (adopting) the dressing and hair-do styles by respondents and their reasons for adopting and not adopting.

\begin{tabular}{ll}
\hline Responses & Frequency (\%) \\
\hline Have you ever practically adopted? (N=23) & \\
Yes & $11(48 \%)$ \\
No & $12(52 \%)$ \\
Reasons for adopting & \\
I think they are moderate and cool & $5(45 \%)$ \\
I feel comfort with them & $4(37 \%)$ \\
Peer pressure & $2(18 \%)$ \\
Reasons for not adopting & \\
My parents don't want & $4(33 \%)$ \\
My religion don't allow & $3(25 \%)$ \\
My school prohibits & $3(25 \%)$ \\
I can't afford & $2(17 \%)$ \\
\hline
\end{tabular}

As shown in the above table, about $48 \%$ of respondents reported to have practically taken up the dressing and/or hair-do styles which they watched on movies/films, TV dramas and/or music clips thinking westerns are modern and cool (45\%). Even though peer influence was seen to be the least factor for adoption, it would arguably enhance collective acceptance of the styles embedded in films or clips and normalization of the particular styles shown. About 33\% of participants were not adopting since their parents don't want it.

\subsection{Pornography Related Issues}

This study focuses on pornography defined as sexually explicit media that are primarily intended to sexually arouse the audience. Sexually explicit representations include images of female or male nudity or semi-nudity, implied sexual activity and actual sexual activity (such as oral sex, vaginal intercourse, anal intercourse and so on). The definition of pornography is broad enough to include media centered on sex and involving only text, such as written materials, but my areas of primary concern are the image-centered media of $\mathrm{X}$-rated videos (8).

\subsubsection{Exposure of Youth to Pornography}

Extent of the exposure to pornography videos were assessed among 108 respondents who first responded that they watched western-based media and cultural entertainment products. Respondents were first asked: Have you ever watched pornography videos? If the respondent agreed then they were asked: How often would that be?

Based on this the finding revealed that more than half $(57.4 \%)$ of males reported that they have watched a pornography video. Among them, (11.4\%) watched on a weekly basis, while $37.2 \%$ watched pornography video at least once a month. Over half of those who watched these videos do so only occasionally. Among girls, only $17 \%$ reported that they have watched a pornography video. The finding of study showed that males and females follow different paths of exposure to pornography. Most females were introduced to pornography materials by someone else, usually male and usually older. Typically, girls watched pornography only once, because a boyfriend or somebody wanted them to or because they were curious, and then did not watch again. In contrast, while the majority of males were also exposed to pornography for the first time through the encouragement of others, in their case this was more likely to be by friends and other males.

Respondents were next asked whether they agree or disagree that watching pornography videos is widespread amongst females and males of their age. So that, about $84 \%$ of both females and males responded that pornography is widespread. This finding is also supported by different scholars, it seemed that males overestimate females use of pornography, in that; while all of females who have done so reported that they watched pornography only once, because a boyfriend or somebody wanted them to or because they were curious, and then did not watch again; $15 \%$ of males believe that watching pornography videos is widespread among females. Males' over-estimation of females' consumption of pornography videos may reflect the assumption that, since use of pornography is common among males, it is also common among females (9). The fact that most males and females believe that watching pornography videos is widespread among males suggests that watching these videos is considered to be normal or at least common behavior among males (10). The normalizing of this activity may give pornography consumption a high degree of tolerance and acceptability within youth culture (11).

\subsubsection{Effects of Exposure to Pornography and Sexual Media Content}

\section{(i). Confusion on the Value of Love and Sex}

To what extent a repeated exposure to pornography videos can affect the viewer's value on love and sex? Some youngsters interviewed for this study expressed how exposure to pornography might contribute to the formation of unhealthy 
attitudes to sex and sexuality which may in turn inhibit the formation of healthy intimate relationships. One interviewee said,

"In western's heterosexual pornography, sex is divorced from intimacy, loving affection, and human connection; sexual partners are constantly available for sex and have very eager sexual appetites; and they are sexually satisfied by whatever each in the film do".

On the other hand, youngsters who saw portrayals of pre-, extra- or non-marital sexual relations may likely rate these portrayals as less bad which may lead them to acceptance of such behaviors. This can best be understood by the words of one informant, who said,

"In our culture, healthy and positive loving relationships were supposed to be unspoiled by the desires of the flesh. But today, where pornographic materials are readily available to most young people who want it, we view in many ways that sexual pleasure is a desirable and the realization of a relationship is to have sex".

Over all, the findings of this study suggest that pornography serves to reduce sexual sincerity and to advocate "love for sex" and "sex for no reason other than pleasure".

\section{(ii). Degrade Females'Sexuality and Shape a \\ Male-Dominant View of Sexuality}

The female informants interviewed described how pornography degrades women. They said that they felt sick, disgusted and upset feeling uncomfortable, shocked, and embarrassed or degraded by the experience. In a troubling sense, they described that pornography has become, in the face of different problems facing women, actually a way to further degrade them. This can best be described in words of one female informant, who said,

"pornography is geared towards the presentation and maximum visibility of the female body, particularly the sexual organ, compared with an almost complete lack of concern for the male body and women are continually repositioned, passively, as object, icon and fetish of male desire"

As per the findings, it is possible to reasonably suggest that pornography can be an important factor in shaping a male dominant view of sexuality. Nonetheless, pornography may not be the sole determinant. Yet this should not be used to discount the voices of other women whose experiences of pornography are more abusive.

\section{(iii). Being Disturbed by Seeing 'Extreme' Behaviors}

Some expressed feelings among interviewees were emotional discomfort or disturbance and even feeling of sexual incompetence while viewing an extraordinary sexual practice. The findings suggest that portrayals of non-mainstream sexual practices are disturbing to some young people precisely because the practices are deviant - they are outside common cultural norms and positioned socially as taboo. While there have been little evidence in this study that support all of young people being upset and emotionally disturbed by depictions of non-mainstream sexual practices in particular, there is no reason to think that this does not occur. This finding is supported by other scholar who says that Pornography videos particularly depict a wide range of sexual practices and relations, including behaviors that may be seen as non-mainstream, deviant or extreme such as anal intercourse, multiple partners, and other strange sexual activities (8).

\section{(iv). Inappropriate Acceptance and Adoption of Non-Mainstream Sexual Practices}

As one informant said, common representations in pornography include images of two or more men engaged in sexual activity with the one woman, sexual activity between two women and one man and other sexual interactions involving multiple participants and portrayals of these extreme sexual behavior may provoke, eroticize and give legitimacy to it. Thus, the argument goes, in viewing images of non-mainstream sexual behavior, youths may come to see such unpleasant practices as acceptable or desirable and may adopt them themselves (11). In addition, some may get confused about their developing sexuality, will tolerate and then adopt a gay or lesbian identity following exposure to homosexual materials. In general, while this study does not totally believe that exposure to pornography is likely to change an individual's entire sexual orientation, it supports that exposure can influence young people's attitudes about and adoption of particular sexual behaviors.

\section{Conclusion}

In general, this research provides good deal of support for some of the assumptions about the impact of foreign media and cultural products on local consumers. Although we cannot generalize from few sample to the whole youth in Hawassa, the findings of this study indicate the potential impact of foreign media content and popular cultural products especially on younger youths who are not only the most active in absorbing foreign media contents and consuming foreign cultural products but also represent the future of the country. The usage of western media by the youth now seems to reach a stage that could affect young people's perception and feelings toward westerns. In terms of western popular cultural products, exposure to western based media is likely to result in a more favorable perception of them in terms of the privileged status attached to their consumption or usage.

As far as the behavioral impact of the usage of western media and popular cultural products is concerned, this study only examined the likelihood of the youngsters to model after the westerns. The western media is more likely to exert modeling effect on youths, making it more likely for them to dress and have a hair-do like the different idols portrayed in movies and music clips. Although this study have not conclusive evidence to prove that all youngsters who use western media and cultural products likely adopt the different 
styles, the data seem to point towards that direction. Nevertheless, those who often watch western movies and music clips tend to consider whatever the western's way of doing things as cool, modern and stylish. Such a phenomenon may leads us to question if this will result in the feeling of being culturally inferior. Further studies should examine if such things really exist.

\section{Acknowledgements}

The authors acknowledge data collectors and participants for their willingness to participate and spent their precious time for the success of the study. The authors also thank school and college principals for their technical support during the study period. Finally the authors acknowledge Dr. Filagot Debebe and W/ro Abebu Jemberie for their financial support to conduct this study.

\section{References}

[1] Giddens A. The consequence of modernity. Stanford, Calif.: Stanford University press, 1990.

[2] Giddens A. Sociology 4th ed. Cambridge: Polity Press, 2005.
[3] Goldman J. Sexuality education for teenagers in the new millennium, 2000. Youth Studies Australia, 19(4), pp.11-17.

[4] Hamlink, C. Cultural autonomy in global communication, 1983. New York: Longman.

[5] Heins, M. Not in Front of the Children: 'Indecency', Censorship, and the Innocence of Youth, 2001. USA, New York.

[6] Hoskins C. Mirus R. Media, Culture \& Society. Reasons for US dominance of the international trade in television programs, 1988. USA, New York.

[7] Kottak C. Mirror of humanity: A concise introduction to Cultural Anthropology, 2005. New York: The McGraw-Hill Companies, Inc.

[8] McNair B. Mediated Sex: Pornography and postmodern culture. London \& New York, 1996.

[9] Levine J. Harmful to Minors: The Perils of Protecting Children From Sex, 2002.

[10] Lull J. Media, communication, culture. Cambridge: Polity Press, 2000.

[11] Matterlart A. Mass media, ideologies and the revolutionary movement, 1980. Sussex: The harvester Press. 